\title{
Erratum to: A new anatomic trait for identifying the mendosal suture in young children: the mendosal-lambdoidal angle
}

\author{
Ilke Ali Gurses ${ }^{1}$ Asim Esenkaya ${ }^{2} \cdot$ Ozcan Gayretli $^{1} \cdot$ Aysin Kale $^{1}$ • \\ Adnan Ozturk ${ }^{1} \cdot$ Aylin Tekes $^{3}$
}

Published online: 19 December 2015

(C) Springer-Verlag France 2015

\section{Erratum to: Surg Radiol Anat \\ DOI 10.1007/s00276-015-1556-y}

The original article was published with an error in the article title. The word "lambdoidal" has been misspelled as "labmdoidal". The correct title should be: "A new anatomic trait for identifying the mendosal suture in young children: the mendosal-lambdoidal angle".

The original article has been updated accordingly.

The online version of the original article can be found under doi:10.1007/s00276-015-1556-y.

Ilke Ali Gurses

iagurses@gmail.com

1 Department of Anatomy, Istanbul Faculty of Medicine, Istanbul University, Millet Caddesi, 34093 Fatih, Istanbul, Turkey

2 Department of Radiology, Cerrahpasa Faculty of Medicine, Istanbul University, Kocamustafapasa Caddesi, No: 53, 34098 Fatih, Istanbul, Turkey

3 Division of Pediatric Radiology, Department of Radiology and Radiologic Science, Johns Hopkins Hospital, Baltimore, MD 21202, USA 